\section{THE LUMLEIAN LECTURES AND MEDICAL RESEARCH.}

To the Editor of THE LANCET.

SiR, - I was much interested in Professor A. R. Cushny's paper on Digitalis in Auricular Fibrillation in your issue of June 9 th, especially in view of the recent correspondence in your columns on the Lumleian lectures. Up to the present it has been assumed that the beneficial action of digitalis in auricular fibrillation is due to the blocking of impulses from auricle to ventricle through stimulation of the inhibitory mechanism of the vagus. But Professor Cushny states in his paper-

That in a number of observations which I made in Mackenzie's wards with Marris and Silberberg we satistied ourselves that in auricular fibrillation the change in conduction is not inhibitory in nature, for it is not prevented by complete paralysis of the vagus by atropine.

Later on he says-

We have two types of digitalis action on the heart. ..... The second or anomalous reaction occurs in the auricular fibrillation in man and not in that experimentally induced in aoimals; here the heart is slowed by direct action on the nuscle independently of the normal inhibitors mechanism.

In his final paragraph Professor Cushny says -

Another result of digitalis on the animal heart is the increase in the sirength of contraction. Does this play no $p$ irt in the improved efticiency of the heart?

Since the advent of electro-cardiography it seems to me that the neurogenic doctrine has been exalted to a position of undue importance, more especially in relation to so-called auricular fibrillation. The irregularity of rhythm in the ventricle in auricular fibrillation is attributed, as far as am aware without any sufficient evidence, to the irregular transmission of feeble, incoördinate stimuli from the flicker ing fibres of the fibrillating auricle, which one would not suppose capable of exciting a contraction in the ventricle. But even admitting this, how can the mere cutting off of a few nervous impulses from auricle to ventricle by itself restore the functional efficiency of a heart muscle that has broken down under stress? Yet that has been the explanation given of the action of digitalis in these cases. It is a great satisfaction, therefore, to find that so distinguished an authority as Professor Cushny has now raised the question as to whether it is not after all increase in the strength of the contraction of the cardiac muscle induced by digitalis, which plays an important part in improving the efficiency of the heart. It is not merely in auricular fibrillation that digitalis is of value. Any clinician knows the extraordinarily satisfactory results obtained from the administration of digitalis in cases of heart failure and dropsy associated with mitral incompetence, even when the pulse is quite regular and there is nu question of "auricular fibrillation." Surel the beneficial effect in these cases is due to the action of digitalis in improving the tonicity of the cardiac muscle, so that the dilatation is reduced. the force of the beat improved, and the quantity of residual blood diminished.

In mitral stenosis. whatever may be the case in the valvular lesions, the heart is working at a great mechanical disadvantage. The left ventricle is small. imperfectly supplied with blood, and has comparatively little work to do. The right ventricle hypertrophies on account of the extra work imposed by the steady increase of pressure in the pulmonary circulation due to the narrow nozzle at the distal end in the form of the stenosed mitral orifice. The pressure in the left auricle is also greatly raised and is an important factor in maintaining as rapid a flow of blood as possible through the narrow orifice during diastole. When the right ventricle fails the pressure in the left ventricle falls and the supply of blood to the left ventricle becomes even more insufficient and irregular. The beneficial action of digitalis in such a case may well be explained by its effect in restoring the tonicity and efficient action of the right ventricle, which is the important factor in maintaining a working circulation. A time must come, however, in severe cases of mitral stenosis at which the almost impassable barrier of the button-hole mitral orifice causes a complete breakdown of the right ventricle, and neither digitalis nor any other drug is of any use in averting the final catastrophe.

To take another point. How is it that digitalis, which has such a beneficial effect in auricular fibrillation, is of no service in paroxysmal tachycardia, Graves's disease, or incleed, in any other form of tachycardia? If it can arrest impulses from auricle to ventricle with beneficial results, as is postulated in auricular fibrillation, why does it fail in the latter group?

The modern conception of heart failure seems to ignore the important fact that there is a right and a left side of the heart, and that we may have failure either of the right or left ventricle, not necessarily of both. In mitral disease the stress falls on the right ventricle, in Bright's disease or high tension in the peripheral circulation on the left ventricle. In the former we get right heart failure eventually, in the latter left heart failure if the patient survives other accidents. In each instance the ventricle, which has most work to do, hypertrophies to meet the extra strain, and digitalis when administered will naturally have its preponderating effect on the side which has the larger mass of muscle.

The inhibitory mechanism of the vagus on the heart has been described as analogous to reins in the hands of a skilled driver controlling a regularly trotting horse. If the horse is exhausted and nearly dead-beat no amount of pulling on the reins will help him on his way; what he needs is a powerful pick-me-up. In the pathological conditions of the heart to which I have alluded above, digitalis, if I may so interpret Professor Cushny's results, appears to act as a direct pickme-up for the exhausted heart muscle rather than as a stimulus to the inhibitory mechanism of the vagus. This is what we might expect from Nature's common-sense methods.

There are many other questions of interest raised by Sir R. Douglas Powell, Dr. Colbeck, and Dr. Alexander Morison in their letters to THE LANCE' of June 9th and 16th, amongst them the question of back pressure and the significance of cardiac murmurs. The disastrous effects of back pressure on the lungs in mitral stenosis are so self-evident, both from the paihological and clinical standpoints, that I do not think it is necessary to $d$ well on them. As regards the significance of murmurs, every clinician knows that the presence of a mitral systolic murmur in itself may be of little importance; what really matters is the degree in which the functional capacity of the heart is impaired, and this one can easily judge by the response of the heart to increased work on exertion and whether or no cardiac symptoms are readily induced thereby. But one cannot afford to ignore the grave effects in mitral stenosis or aortic lesions of any serious degree on the hydraulics of circulation and the mechanical embarrassment of the heart entailed thereby, apart from other considerations.

That work of the greatest importance has been done by Sir James Mackenzie by his polygraphic tracings and by Lewis with the electrocardiograph in elucidating the problems of heart-block, extra-systole, and sinus arrhythmia I should be the first to admit, but for the reasons given above I am unable to accept in its entirety the doctrine of auricular fibrillation.-I am, Sir, yours faithfully,

Seymour-street, W., June 18th, 1917. JOHN F. H. BROADBENT.

\section{THE USE OF POLYVALENT VACCINES IN DYSENTERY.}

To the Editor of THE LANCET.

Sir,-As a result of the investigations of Dr. J. H. Harvey Pirie on the bacilli causing dysentery in African natives in the Carrier Corps depôt at Nairobi, it was decided to try the effect of a polyvalent vaccine as a therapeutic measure. From the literature available it appeared that the drawback to antidysenteric vaccines was their extremely toxic character. It was thought that possibly the heat used to sterilise the vaccines might be in some way a cause of this toxicity and it was decided to try to prepare a vaccine sterilised by antiseptics alone.

The first antiseptic tried was eusol, but, although the solution was freshly prepared, it was found that it failed to sterilise the cultures, even when added in large doses. Recourse was then had to 0.4 per cent. carbolic acid, the antiseptic employed in this laboratory in the preparation of autogenous vaccines. It was found that the addition of this strength of carbolic acid brought about complete sterilisation in about two days.

Dr. Pirie selected from his stock of local strains a Shiga bacillus and bacillus of the Morgan type. These were incubated in peptone broth for 48 hours at $37^{\circ} \mathrm{C}$. The cultures were then carbolised and tested for sterility after 48 hours. The vaccine was administered to Africans 
suffering from dysentery at the Carrier Depôt Hospital, Nairobi, and it was found to cause no toxic symptoms. The treatment was begun on Sept. 1st, 1916, and since then 350 cases have been treated or are under treatment at the time of writing. The results have been most promising, and at a later date it is proposed to publish complete statistics. The majority of cases respond immediately, and others which do not show much marked improvement are often complicated by bilharziasis.

The vaccine has since had a bacillus of the type Flexner added, with improved results. It now consists of six different strains in the following proportions: $B$. Shiga, 1 part; bacillus resembling $B$. Shigx in all its sugar reactions, but motile, 1 part ; bacillus of the $B$. Flexner type, 1 part ; three different strains of the $B$. Morgan type, 3 parts. The cultures are made in flasks of peptone broth and grown for three days at $37^{\circ} \mathrm{O}$. They are then carbolised, tested for sterility after two days, mixed in the above proportions and issued as required.

Therapeutic inoculation was first attempted with a dose of 5,000,000 B. Shiga and 5,000,000 of mixed strains of $B$. Morgan type, increasing by 5,000,000 daily, but it was found that more satisfactory results were obtained with large doses at longer intervals. The usual dose at present is 1 c.c. of the vaccine, made in the manner and proportions described above, on the day of admission. On the eighth day 2 c.c. are injected subcutaneously; on the fifteenth day 3 c.c. and, if necessary, on the twenty-second day 4 c.c. Still larger doses are being tried at the time of writing, but it is too early yet to form an opinion as to whether these bigger doses are advisable or not.

In addition to the use of the vaccine as a therapeutic measure African porters passing through Nairobi Depôt are being submitted to prophylactic inoculation. Unfortunately, so far no figures are available to show whether this inoculation is of any value or not.

We are, Sir, yours faithfully,

PhILIP H. Ross,

Director of Laboratories, British East Africa ; Honorary Adviser to the Director of Medical Services, E.A.F. W. H. KAUNTZE,

Captain, West African Medical Staff (attached East African Medical Service).

\section{THE POPULATION OF ASYLUMS FOR THE INSANE.}

To the Editor of THE LANCET.

SIR,-For some time past the Daily Graphic has been publishing articles vituperating public asylums and all connected with them. On June 13th this newspaper prints a long article entitled "Heroes in Asylums." Nearly onehalf of this is taken up with the correspondence of a person who writes: "I have been detained by the Lunacy Commissioners ever since December, 1905, as a lunatic." Further on it states that a patient was visited by a Daily Graphic representative, who we must suppose is an expert, and who could find nothing the matter except "twitching of the nerves $(s i c)$ and a highly strung manner which is typical of nervous patients." This kind of nonsense has been read by many and if no reply is made the public naturally say that " silence is consent." Writing to the Daily Graphic has been tried, but the letter was not inserted. I am writing therefore to crave the indulgence of your columns and to state that the article in question contains numerous inaccuracies, to put it as mildly as possible. This information is not needed by your readers, but I am hoping that through the instrumentality of medical men the public may learn where the truth lies. In the Times on the same day a coroner is reported to have stated that it was a scandal that so many insane patients were discharged from asylums. I am, Sir, yours faithfully,

R. H. STEEN.

City of London Mental Hospital, near Dartford, Kent, June 15th, 1917 .

IRISH MEDICAL AsSOCIATION.-The annual general meeting of this association was held on June 14th, Dr. R. Marlay Blake presiding. Some discussion took place with reference to the Midwives Bill for Ireland which has been drafted by the Local Government Board, and the opinion was expressed that the Bill should be submitted to the medical profession before being introduced to Parliament.

\section{The gatar.}

\author{
The Casualty List.
}

THe following names of medical officers appear among the casualties announced since our last issue :-

\section{Killed.}

Capt. F. J. H. T. Frere, M.C., R.A.M.C., qualified at Durham in 1913 and held the appointment of house surgeon at Newcastle Royal Infirmary. He joined the R.A.M.C. on the outbreak of war and saw service in Gallipoli. The award of the Military Cross was announced in THE LANCET of Feb. 5th, 1916, p. 321.

Capt. O. Hairsine, M.C., R.A.M.C., was a student at Middlesex Hospital, and qualified in 1914, just prior to the outbreak of war, and thereupon joined the R.A.M.C. Capt. Hairsine was in the retreat from Mons, and the award of his Military Cross was recorded in THE LAANCET of Jan. 22nd, 1916, p. 215

Capt. L. E. Clark, Canadian A.M.C.

Capt. D. R. King, R.A.M.C., qualified at Glasgow in 1914 and shortly afterwards joined up.

$$
\text { Died of Wounds. }
$$

Lieut. W. A. Smith, R.A.M.C., attached Royal Field Artillery。

$$
\text { Wounded. }
$$

Capt. O. De Muth, R.A.M.C.

Lieut. A. G. H. Smart, R.A.M.C.

Capt. W. M. Cox, R.A.M.C.

Capt. A. C. Giles, R.A.M.C., attached S. Lanc. Regt.

Capt. J. McMillan, R.A.M.C., attached M.G.C.

Col. A. W. N. Bowen, R.A.M.C.

Capt. P. Hudson, R.A.M.C., attached Hamps. Regt.

Capt. W. B. Loveless, R.A.M.C., attached R. W. Regt.

Capt. H. C. D. Miller, R.A.M.C.'

Capt. C. Witts, M.C., R.A.M.C., attached High. I.I.

Capt. K. J. Yeo, R.A.M.C., attached M.G.C.

Capt. J. J. Sinclair, R.A.M.C.

Capt. C. H. Carlton, R.A.M.C., attached London Regt.

Capt. A. J. McCreadie, R.A.M.C., attached Border Regt.

Capt. A. C. Court, R.A.M.C.

Capt. R. O. H. Jones, R.A.M.C

Capt. J. Marshall, New Zealand M.C.

\section{Casualties among the Sons of Medical Men.}

The following additional casualties among the sons of medical men are reported :--

Second Lieutenant C. P. Lewis, Royal Engineers, killed in action, only son of Dr. P. Lewis, of Brixton-hill, London, S.W.

Second Lieutenant I. H. McCaw, Royal Irish Rifles, wounded, only son of Dr. J. McCaw, of Dublin-road, Belfast.

Second Lieutenant C. L. Green, Essex Regt., attached Royal Flying Corps, killed in action, elder son of Dr. E. F.S. Green, of South Norwood, London, S.E.

\section{The Remuneration of The Medicat Staffas of \\ V.A.D. Hospitals.}

It is now some time since Dr. Howard Marshall raised the question in a letter to the Times of the remuneration of the medical staffs of V.A.D. hospitals, but nothing has been done to place the position of these officers on a satisfactory basis. It has come out, mainly as the result of Dr. Marshall's action, that two years ago a form was issued, under the authority of a War Office letter, to the various commands, in accordance with which remuneration could be claimed by the medical officers of V.A.D. hospitals, but the existence of the form was not made known to the medical officers. Further, the remuneration, when given to certain of the officers, was construed as a private transaction. It may be that many medical officers of V.A.D. hospitals are prepared to give their services gratuitously and to defray their own out-of-pocket expenses, but to many others this must be a grave hardship. The whole question has for some time been under the consideration of the Central Medical War Committee, and it is essentially one where the War Office authorities should be ready to coöperate with that body and other representative bodies in putting matters on a sound financial footing. 